\title{
Battle to Death
}

\author{
CLIFF SHAW, Yorkton
}

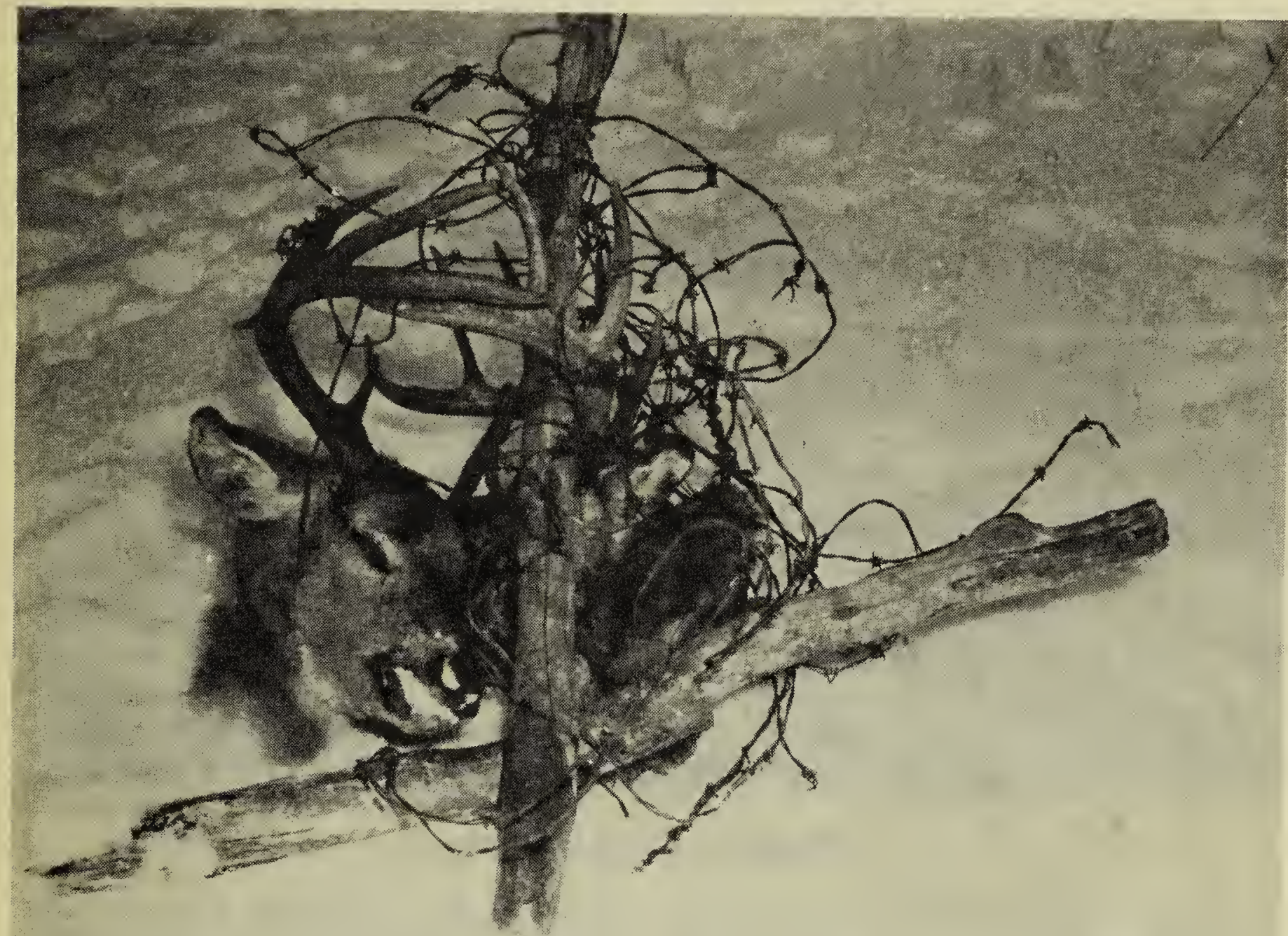

Poem by Dr. H. S. Swallow, Yorkton.

Evidence of one of nature's struggles for existence are these two deer heads, locked in battle and entwined with over 50 feet of barbed wire and two fence posts. The animals were found by Norman Allan on the farm of Alex Phelps in the Crescent Lake district, south of Yorkton. The two bucks, one a four-pointer and the other a five, had apparently started their argument on either side of a farm fence. In their battle to death they tore up almost 100 feet of fence line and in their struggle wrapped half of it around their horns.

They fought for mastery and the right

To lead the herd and propogate their kind.

But, blind, mad, passion posed as fate,

Locked horns and cruel wire both did bind.
Dumb animals, we lightly say, and go our way,

And leave their forms within that quiet glen -

Forgetting, just how often, blind, mad passion wrecks

The lives of some who pose, as wiser men.

Nature Notes (from Page 7)

Bohemian Waxwings, generally seen in small flocks, are with us by the hundreds. Pine Grosbeaks and Evening Grosbeaks are also quite numerous. The latter are especially welcome as they prevent our being overhwhelmed by the Manitoba Maples, many of which are loaded with winged seeds which these beautiful birds eat greedily.

Chickadees and Hairy and Downy Woodpeckers are constant visitors to a maple tree, just outside the kitchen window. 